\title{
HUBUNGAN STRATEGI PEMASARAN DENGAN PREFERENSI PASIEN POLIKLINIK ANAK DI RUMAH SAKIT X MEDAN
}

\section{The Relationship Of Marketing Stategies With The Preferences Of Pediatric Clinic Patient At Hospital X Medan}

\author{
Nisrina1, Destanul Aulia², Lita Andayani $^{3}$ \\ ${ }^{1}$ Program Studi S2 Ilmu Kesehatan Masyarakat Universitas Sumatera Utara Medan \\ ${ }^{2}$ Program Studi S2 Ilmu Kesehatan Masyarakat Universitas Sumatera Utara Medan \\ ${ }^{3}$ Program Studi S2 Ilmu Kesehatan Masyarakat Universitas Sumatera Utara Medan
}

\begin{abstract}
Abstrak
Pelayanan yang ditawarkan di rumah sakit merupakan salah satu faktor yang mempengaruhi pilihan pasien. Pelayanan poliklinik anak dengan dokter spesialis anak yang terpercaya merupakan daya tarik rumah sakit bagi pasien. Selain itu, pada survey didapati bahwa pasien cenderung memilih rumah sakit karena saran keluarga, kebiasaan di lingkungannya serta kualitas pelayanan kesehatan Penelitian ini bertujuan untuk menganalisis hubungan strategi pemasaran dengan preferensi pasien Poliklinik Anak di Rumah Sakit X Medan. Jenis penelitian ini adalah penelitian kuantitatif, dengan melakukan survey analitik (explanatory study) menggunakan pendekatan potong lintang (cross sectional). Penelitian dilakukan di Poliklinik Anak Rumah Sakit X dari bulan Maret 2019 sampai dengan bulan Mei 2019 dengan sampel sebesar 65 orang. Metode analisis data dalam penelitian ini adalah dengan menggunakan analisis Chi Square. Hasil analisis menunjukkan bahwa variabel produk ( $\mathrm{p}$ value $=0,001$ ), dan promosi ( $\mathrm{p}$ value $=0,001$ ) memiliki hubungan yang signifikan dengan variabel preferensi pasien di Poliklinik Anak Rumah Sakit X, Pihak rumah sakit disarankan untuk memberikan perhatian pada beberapa unsur kualitas produk pelayanan dan memaksimalkan promosi untuk memperkenalkan layanan kesehatan poliklinik anak.

Kata kunci: Preferensi pasien, Strategi pemasaran, Poliklinik anak
\end{abstract}

\begin{abstract}
Services in hospitals are one of the factors that influence patient preferences. The service of a pediatric polyclinic with a trusted pediatrician is a hospital attraction for patients. Initial survey of the study presented that patients tended to choose hospitals because of families, habits in their environment and health service quality. This study aims to analyze the relationship of marketing strategies with the preferences of Pediatric clinic patients at Hospital $\mathrm{X}$. This quantitative research was carried out by performing an analytical survey (explanatory study) using a cross sectional approach. The study was conducted at the Pediatric clinic in X Hospital from March 2019 to May 2019 with sample amounted to 65 people. The method of data analysis in this study using the chi square analysis. The analysis showed that the variables of product ( $\mathrm{p}$ value $=0.001$ ), and promotion ( $\mathrm{p}$ value $=0.001$ ) had a significant relationship with patient preferences of pediatric polyclinic at $\mathrm{X}$ Hospital. The hospital is advised to pay attention to some elements of the quality of service products and maximize promotion to introduce health service of pediatric polyclinic.
\end{abstract}

Keywords: Patient Preferences, Marketing Strategies, Pediatric Clinic

Korespondensi: Nisrina

Email: nisrina.ars16@gmail.com

\section{PENDAHULUAN}

Rumah sakit ialah sebuah lembaga yang berwenang untuk melaksanakan pelayanan kesehatan komprehensif. Pelayanan yang diberikan berupa rawat jalan, rawat inap serta kegawatdaruratan (Undang-Undang Nomor 44/2009). WHO Expert Committee On Organization of Medical Care menyatakan bahwa rumah sakit sebagai organisasi medis serta sosial memiliki peran untuk melaksanakan perawatan secara komprehensif baik dengan cara preventif maupun kuratif. Selain daripada itu rumah sakit memiliki fungsi sebagai pusat pendidikan calon tenaga kesehatan serta berfungsi sebagai tempat riset biososial. 
Persaingan pesat antar rumah sakit mendorong peningkatan mutu jasa kesehatan yang diberikan kepada pasien. Implementasi mutu jasa yang dilaksanakan suatu sarana jasa kesehatan adalah memberikan jasa yang terbaik untuk menciptakan kepuasan pasien. Preferensi pasien juga mempengaruhi persaingan rumah sakit. Preferensi berasal dari kata preference yang berarti "a greater liking for one alternative over another or others" (kesukaan atas suatu hal dibandingkan dengan hal lainnya).

Preferensi pasien menggambarkan rumah sakit mana yang merupakan keputusan final pasien tersebut untuk berobat. Pemahaman tentang preferensi sangat penting bagi pihak manajemen rumah sakit agar dapat meningkatkan mutu pelayanan dan mendapatkan lebih banyak pasien.

Empat faktor yang mempengaruhi preferensi pasien yaitu : pengaruh psikologis, pengaruh strategi pemasaran, pengaruh sosiokultural dan pengaruh situasional ${ }^{1}$. Jasa yang ditawarkan rumah sakit menjadi aspek yang mempengaruhi pilihan pasien. Pelayanan poliklinik anak dengan dokter spesialis anak yang terpercaya merupakan daya tarik rumah sakit bagi pasien. Harga yang harus dibayar juga menjadi pertimbangan pasien sebelum memutuskan. Beberapa orang memutuskan menggunakan layanan kesehatan berdasarkan promosi yang pernah dilihatnya, baik melalui media cetak maupun elektronik. Tempat merupakan hal yang tidak kalah penting dalam pemilihan rumah sakit oleh pasien.

Rumah sakit yang terletak di jalan utama kawasan Medan Utara yaitu jalan K.L. Yos Sudarso cenderung memiliki lebih banyak pasien karena lebih mudah diakses. Berdasarkan pengamatan peneliti rumah sakit $\mathrm{X}$ memiliki pasien paling banyak dibandingkan kelima rumah sakit lain yang setipe di kawasan Medan Utara. Merujuk pada teori preferensi pasien maka faktor strategi pemasaran lebih relevan untuk diteliti untuk mengetahui mengapa pasien lebih stertarik untuk menggunakan jasa pelayanan kesehatan di rumah sakit ini.

\section{METODE}

Penelitian ini adalah penelitian kuantitatif, dengan melakukan survey analitik (explanatory study) menggunakan pendekatan potong lintang (cross sectional). Penelitian dilakukan di Poliklinik Anak Rumah Sakit X dari bulan Maret 2019 sampai dengan bulan Mei 2019 dengan sampel sebesar 65 orang. Metode analisis data dalam penelitian ini adalah dengan menggunakan analisis Chi Square.

\section{HASIL PENELITIAN}

Distribusi frekuensi karakteristik responden dikategorikan berdasarkan data yang meliputi, umur, pendidikan, pekerjaan, dan pendapatan, dapat dilihat pada tabel dibawah ini.

Distribusi responden,dapat diketahui bahwa dari 65 responden yang diamati, mayoritas responden berumur produktif yaitu ada sebanyak 63 responden (96,9\%), berpendidikan tinggi yaitu ada sebanyak 63 responden $(96,9 \%)$, status bekerja yaitu ada sebanyak 52 responden $(80,0 \%)$, dengan pendapatan tinggi yaitu sebanyak 40 responden $(61,5 \%)$.

Tabulasi silang antara produk dengan preferensi pasien bahwa dari 65 responden yang diamati, terdapat sebanyak 52 responden yang menganggap kualitas produk baik yang mempunyai preferensi pasien yang positif. Berdasarkan hasil analisis diperoleh nilai probabilitas variabel produk $(p$ value $=0,001)$ dengan preferensi pasien poliklinik anak Rumah Sakit X. Artinya, bahwa terdapat hubungan yang signifikan antara variabel produk dengan preferensi pasien poliklinik anak di Rumah Sakit X.

Tabulasi silang antara harga dengan preferensi pasien bahwa dari 65 responden yang diamati, terdapat sebanyak 47 
responden yang menganggap harga sudah sesuai dan 18 responden yang menganggap harga tidak sesuai, Berdasarkan hasil analisis diperoleh nilai probabilitas variabel harga $(p$ value $=0,061)$ dengan preferensi pasien poliklinik anak. Artinya, bahwa tidak terdapat hubungan yang signifikan antara variabel harga dengan preferensi pasien poliklinik anak di Rumah Sakit X.

Tabulasi silang antara promosi dengan preferensi pasien bahwa dari 65 responden yang diamati, terdapat sebanyak 55 responden yang menganggap promosi rumah sakit sudah efektif, sedangkan 10 responden yang menganggap promosi rumah sakit belum efektif, Berdasarkan hasil analisis diperoleh nilai probabilitas promosi pada preferensi pasien adalah $\mathrm{p}=0,019<0,05$, hal ini bermakna bahwa terdapat hubungan yang signifikan antara promosi dengan preferensi pasien poliklinik anak Rumah Sakit X.

Tabulasi silang antara tempat dengan preferensi pasien bahwa dari 65 responden yang diamati, terdapat sebanyak 55 responden yang menganggap tempat sudah baik, sedangkan 10 responden yang menganggap tempat belum baik. Pada hasil analisis diperoleh nilai probabilitas variabel tempat $(p$ value $=0,071)$ dengan preferensi pasien poliklinik anak Rumah Sakit X. Artinya, bahwa tidak terdapat hubungan yang signifikan antara variabel tempat dengan preferensi pasien poliklinik anak di Rumah Sakit X.

Tabel 1. Distribusi Frekuensi Berdasarkan Karakteristik Responden Rumah Sakit X

\begin{tabular}{|c|c|c|}
\hline Variabel & $\mathrm{n}$ & $\%$ \\
\hline \multicolumn{3}{|l|}{ Umur } \\
\hline Produktif & 63 & 96,9 \\
\hline Tidak Produktif & 2 & 3,1 \\
\hline \multicolumn{3}{|l|}{ Pendidikan } \\
\hline Tinggi & 63 & 96,9 \\
\hline Rendah & 2 & 3,1 \\
\hline \multicolumn{3}{|l|}{ Pekerjaan } \\
\hline Bekerja & 52 & 80,0 \\
\hline Tidak Bekerja & 13 & 20,0 \\
\hline \multicolumn{3}{|l|}{ Pendapatan } \\
\hline Tinggi & 40 & 61,5 \\
\hline Rendah & 25 & 38,5 \\
\hline
\end{tabular}

Tabel 2. Tabulasi Silang Antara Produk dengan Preferensi Pasien Rumah Sakit X

\begin{tabular}{|c|c|c|c|c|c|c|c|}
\hline \multirow{3}{*}{ Produk } & \multicolumn{4}{|c|}{ Preferensi Pasien } & \multirow{2}{*}{\multicolumn{2}{|c|}{ Total }} & \multirow{3}{*}{$P$ value } \\
\hline & \multicolumn{2}{|c|}{ Positif } & \multicolumn{2}{|c|}{ Negatif } & & & \\
\hline & $\mathrm{n}$ & $\%$ & $\mathrm{n}$ & $\%$ & $\mathrm{n}$ & $\%$ & \\
\hline Baik & 52 & 100,0 & 0 & 0 & 52 & 100,0 & \multirow{3}{*}{0,001} \\
\hline Tidak Baik & 3 & 23,1 & 10 & 76,9 & 13 & 100,0 & \\
\hline Total & 55 & 84,6 & 10 & 15,4 & 65 & 100,0 & \\
\hline
\end{tabular}


Tabel 3. Tabulasi Silang Antara Harga dengan Preferensi Pasien Rumah Sakit X

\begin{tabular}{|c|c|c|c|c|c|c|c|}
\hline \multirow{3}{*}{ Harga } & \multicolumn{4}{|c|}{ Preferensi Pasien } & & & \multirow{3}{*}{$p$ value } \\
\hline & \multicolumn{2}{|c|}{ Positif } & \multicolumn{2}{|c|}{ Negatif } & \multicolumn{2}{|c|}{ Total } & \\
\hline & $\mathrm{n}$ & $\%$ & $\mathrm{n}$ & $\%$ & $\mathrm{n}$ & $\%$ & \\
\hline Sesuai & 45 & 95,7 & 2 & 4,3 & 47 & 100,0 & \\
\hline Tidak Sesuai & 10 & 55,6 & 8 & 44,4 & 18 & 100,0 & 0,061 \\
\hline Total & 55 & 84,6 & 10 & 15,4 & 65 & 100,0 & \\
\hline
\end{tabular}

Tabel 4. Tabulasi Silang Antara Promosi dengan Preferensi Pasien Rumah Sakit X

\begin{tabular}{|c|c|c|c|c|c|c|c|}
\hline \multirow{3}{*}{ Promosi } & \multicolumn{4}{|c|}{ Preferensi Pasien } & \multirow{2}{*}{\multicolumn{2}{|c|}{ Total }} & \multirow{3}{*}{$p$ value } \\
\hline & \multicolumn{2}{|c|}{ Positif } & \multicolumn{2}{|c|}{ Negatif } & & & \\
\hline & $\mathrm{n}$ & $\%$ & $\mathrm{n}$ & $\%$ & $\mathrm{n}$ & $\%$ & \\
\hline Efektif & 49 & 89,1 & 6 & 10,9 & 55 & 100,0 & \\
\hline Tidak Efektif & 6 & 60,0 & 4 & 40,0 & 10 & 100,0 & 0,019 \\
\hline Total & 55 & 84,6 & 10 & 15,4 & 65 & 100,0 & \\
\hline
\end{tabular}

Tabel 5. Tabulasi Silang Antara Tempat dengan Preferensi Pasien Rumah Sakit X

\begin{tabular}{|c|c|c|c|c|c|c|c|}
\hline \multirow{3}{*}{ Tempat } & \multicolumn{4}{|c|}{ Preferensi Pasien } & & & \multirow{3}{*}{$P$ value } \\
\hline & \multicolumn{2}{|c|}{ Positif } & \multicolumn{2}{|c|}{ Negatif } & \multicolumn{2}{|c|}{ Total } & \\
\hline & $\mathrm{n}$ & $\%$ & $\mathrm{n}$ & $\%$ & $\mathrm{n}$ & $\%$ & \\
\hline Baik & 51 & 92,7 & 4 & 7,3 & 55 & 100,0 & \\
\hline Tidak Baik & 4 & 40,0 & 6 & 60,0 & 10 & 100,0 & 0,071 \\
\hline Total & 55 & 84,6 & 10 & 15,4 & 65 & 100,0 & \\
\hline
\end{tabular}

\section{PEMBAHASAN}

Analisis variabel produk pada penelitian ini mendukung penelitian sebelumnya yang mendapati bahwa pasien di Oman cenderung memilih rumah sakit swasta daripada rumah sakit pemerintah karena kualitas produk atau layanan kesehatan yang ditawarkan oleh rumah sakit swasta lebih baik ${ }^{3}$. Kelengkapan fasilitas dan pelayanan yang ramah juga menjadi nilai tambah bagi rumah sakit swasta. Kualitas pelayanan adalah atribut utama yang mempengaruhi preferensi pasien ${ }^{4}$.

Kualitas merupakan suatu kondisi dinamis yang berhubungan dengan produk, jasa, manusia, proses dan lingkungan yang memenuhi atau melebihi harapan ${ }^{1}$ Terdapat lima dimensi kualitas jasa yang perlu diperhatikan pihak rumah sakit. Dimensi pertama adalah keandalan (reliability), yaitu kemampuan untuk memberikan pelayanan yang dijanjikan dengan tepat. Dimensi kedua adalah daya tanggap (responsiveness), yaitu kemauan para karyawan untuk membantu memberikan jasa yang dibutuhkan konsumen. Dimensi ketiga adalah jaminan (assurance) yang meliputi pengetahuan, kemampuan, keramahan, kesopanan, dan sifat dapat dipercaya. Dimensi keempat adalah empati untuk memahami kebutuhan dan kesulitan, konsumen, Dimensi kelima adalah produk fisik (tangibles) yang harus ada dalam proses jasa ${ }^{5}$. Kelima dimensi ini perlu mendapat perhatian lebih dari manajemen rumah sakit agar kualitas pelayanan sesuai harapan pasien.

Perhatian pada kualitas produk semakin meningkat selama beberapa tahun belakangan ini. Hal ini terjadi karena keluhan konsumen yang semakin lama semakin terpusat pada 
kualitas yang buruk dari produk baik pada bahan maupun pekerjaannya. Meskipun kualitas produk atau jasa mutlak harus ada, dalam pelaksanaannya faktor ini merupakan ciri produk yang paling sulit dijabarkan. Konsumen sering tidak sependapat tentang faktor-faktor apa yang sebenarnya membentuk kualitas sebuah produk. Pada dasarnya produk harus mampu mencapai tingkat kualitas yang sesuai dengan penggunaannya. Konsumen akan memiliki harapan mengenai bagaimana produk atau jasa tersebut seharusnya digunakan (performance expectation).

Harga adalah sejumlah uang yang menjadi kewajiban bagi konsumen untuk dibayarkan guna mendapatkan suatu produk atau jasa yang dibutuhkan atau dikehendaki konsumen ${ }^{1}$. Harga merupakan sejumlah uang yang diperlukan agar dapat ditukar dengan suatu produk atau jasa yang dapat mencapai kebutuhan konsumen. Harga mempunyai fungsi utama pada preferensi pasien.

Mayoritas responden menganggap bahwa harga yang ditetapkan oleh pihak rumah sakit sudah sesuai dengan pelayanan kesehatan yang diberikan. Harga yang ditetapkan oleh rumah sakit juga dianggap dapat bersaing dengan rumah sakit lain oleh sebagian besar responden.

Promosi adalah semua jenis kegiatan pemasaran yang ditujukan untuk mendorong permintaan konsumen atas produk yang ditawarkan produsen atau penjual. Adapun tujuan promosi adalah; (1) memodifikasi tingkah laku konsumen, (2) memberitahukan atau menginformasikan produk kepada konsumen, (3) membujuk dan memotivasi konsumen agar mau membeli produk yang ditawarkan, dan yang terakhir mengingatkan konsumen tentang produk agar tidak beralih ke produk lain. Terdapat 4 jenis kegiatan dalam promosi suatu produk antara lain, periklanan, penjualan perorangan, promosi penjualan, dan publisitas ${ }^{5}$.

Publisitas adalah kegiatan yang seharusnya paling ditonjolkan dalam kegiatan promosi suatu rumah sakit. Kegiatan publisitas yang dapat dilakukan misalnya seminar kesehatan yang mengundang masyarakat umum, dimana di sela-sela kegiatan dapat diinformasikan tentang rumah sakit, layanan serta fasilitasnya. Bakti sosial pada masyarakat sekitar rumah sakit juga dapat menjadi sarana publisitas yang efektif. Pengoptimalan website rumah sakit dengan menambahkan informasi-informasi kesehatan serta konsultasi online juga dapat menjadi alternatif promosi.

Terdapat lima faktor yang harus dipertimbangkan untuk melaksanakan program promosi, yaitu (1) pemasar harus menentukan besarnya budget promosi, (2) pemasar harus merancang suatu kondisi untuk berpartisipasi, (3) pemasar harus memutuskan lamanya promosi, (4) pemasar harus memilih sarana promosi, dan (5) pemasar harus menentukan waktu promosi ${ }^{5}$.

Hasil penelitian ini mendukung hasil penelitian sebelumnya yang mendapati bahwa di Jerman pasien membuat keputusan untuk memilih layanan rumah sakit berdasarkan informasi yang didapatkannya dari website rumah sakit tersebut. Pasien membandingkan informasi yang didapatnya dari beberapa website rumah sakit sehingga ia dapat memutuskan rumah sakit mana yang menyediakan layanan yang paling sesuai untuknya ${ }^{6}$.

Tempat dalam jasa adalah kombinasi antara letak tempat tersebut dengan cara untuk menyampaikan jasa untuk konsumen dan dimana lokasi yang strategis. Seringkali lokasi menjadi faktor yang sangat krusial dalam menentukan kesuksesan suatu rumah sakit. Lokasi adalah salah satu dari sekian banyak perhatian konsumen ketika melakukan penentuan terhadap pilihannya pada sebuah pelayanan ${ }^{5}$.

\section{KESIMPULAN DAN SARAN}


Kesimpulan yang didapat dari penelitian ini adalah strategi pemasaran khususnya variabel produk dan promosi berhubungan dengan preferensi pasien. Kualitas pelayanan yang baik serta kemudahan memperoleh informasi tentang rumah sakit membuat pasien lebih memilih menggunakan layanan poliklinik anak di rumah sakit ini.

Berdasarkan hasil analisis, saran yang dapat penulis berikan adalah pihak rumah sakit perlu memberikan perhatian pada beberapa unsur kualitas produk pelayanan poliklinik anak seperti jasa dokter, obat-obat dan alat-alat kesehatan harus dimaksimalkan dengan mengadakan pembaharuan dan penambahan sarana dan prasarana untuk menunjang kualitas pelayanan kesehatan.

Pihak rumah sakit dapat membuat PR Plan (Public Relation Plan). PR Plan yang dimaksud adalah dengan melakukan kegiatan untuk meningkatkan awareness masyarakat terhadap pelayanan rumah sakit. Kegiatan yang dapat dilakukan misalnya, seminar kesehatan tentang isu kesehatan terkini dengan mengundang masyarakat sehingga masyarakat mendapatkan informasi kesehatan dan pihak rumah sakit dapat memperkenalkan layanan rumah sakit, Mengoptimalkan website yang telah dimiliki oleh rumah sakit dengan menambahkan informasi kesehatan dan layanan konsultasi kesehatan online.

\section{DAFTAR PUSTAKA:}

1. Kotler, P. 2015. Manajemen Pemasaran. Salemba Empat, Jakarta.

2. Bastemeijer..2016. What Do Patient Values and Preference Mean? A Taxonomy Based On Systematic Review of Qualitative Papers. www.elsevier.com.

3. Mohammed.2017. Factors Influencing the Preferences of Private Hospitals to Public Hospitals in Oman. www.pubmed.com.

4. Kobayashi.2013. Patient's Preference on Selecting Medical Institution. www.pubmed.com.

5. Sangadji. 2013. Perilaku Konsumen. Penerbit Andi. Yogyakarta.
6. Schuldt.2017. Insurees Preferences in Hospital Choice-A Population Based Study. www.sciencedirect.com. 